\title{
Nitric Oxide Enhances Rice Resistance to Rice Black-Streaked Dwarf Virus Infection
}

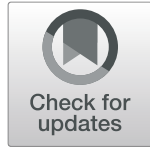

Rongfei Lu ${ }^{1,2 \dagger}$, Zhiyang Liu' ${ }^{1 \dagger}$, Yudong Shao ${ }^{1,2}$, Jiuchang Su${ }^{2}$, Xuejuan $\mathrm{Li}^{1}$, Feng Sun ${ }^{1}$, Yihua Zhang ${ }^{2}$, Shuo Li ${ }^{1}$, Yali Zhang ${ }^{3}$, Jin Cui ${ }^{2}$, Yijun Zhou', Wenbiao Shen ${ }^{2^{*}}$ and Tong Zhou ${ }^{1,4^{*}}$

\begin{abstract}
Background: Rice black-streaked dwarf virus (RBSDV) causes one of the most important rice virus diseases of plants in East Asia. However, molecular mechanism(s)controlling rice resistance to infection is largely unknown.

Results: In this paper, we showed that RBSDV infection in rice significantly induced nitric oxide (NO) production. This finding was further validated through a genetic approach using a RBSDV susceptible (Nipponbare) and a RBSDV resistant (15HPO187) cultivar. The production of endogenous NO was muchhigher in the $15 \mathrm{HPO} 187$ plants, leading to a much lower RBSDV disease incidence. Pharmacological studies showed that the applications of NO-releasingcompounds (i.e., sodium nitroprusside [SNP] and nitrosoglutathione [GSNO]) to rice plants reduced RBSDV disease incidence. After RBSDV infection, the levels of OSICS1, OSPR16 and OsWRKY 45 transcripts were significantly up-regulated by NO in Nipponbare. The increased salicylic acid contents were also observed. After the SNP treatment, protein S-nitrosylation in rice plants was also increased, suggesting that the NO-triggered resistance to RBSDV infection was partially mediated at the posttranslational level. Although Osnia2 mutant rice produced less endogenous NO after RBSDV inoculation and showed a higher RBSDV disease incidence, its RBSDV susceptibility could be reduced by SNP treatment.
\end{abstract}

Conclusions: Collectively, our genetic and molecular evidence revealed that endogenous NO was a vital signal responsible for rice resistance to RBSDV infection.

Keywords: Rice, Rice black-streaked dwarf virus, Nitric oxide, Sodium nitroprusside, Osnia2 mutant rice

\section{Background}

Rice black-streaked dwarf virus (RBSDV) is a member in the Genus Fijivirus, family Reoviridae. RBSDV is known to be transmitted by small brown planthopper (SBPH, Laodelphax striatellus) in a persistent manner (Shikata and Kitagawa 1977; Hibino 1996; Feng et al. 2019), and can cause severe damages to rice (Oryza sativa), maize (Zea mays), and several other cereal crops in the eastern region of Asia. RBSDV symptoms in rice plants include plant stunting, leaf dark greening, pale green enation formation, and dark color leaf vein swellings (Bai et al. 2002; Chen and Zhang 2005;

\footnotetext{
* Correspondence: wbshenh@njau.edu.cn; zhoutong@jaas.ac.cn

${ }^{\dagger}$ Rongfei Lu and Zhiyang Liu contributed equally to this work.

${ }^{2}$ College of Life Sciences, Laboratory Center of Life Sciences, Nanjing

Agricultural University, Nanjing 210095, China

'Key Laboratory of Food Quality and Safety, Institute of Plant Protection, Jiangsu Academy of Agricultural Sciences, Nanjing 210014, Jiangsu Province, China Full list of author information is available at the end of the article
}

Lee et al. 2005). It was previously reported that phytohormones played crucial roles in rice resistance to RBSDV infection. For example, during RBSDV infection in rice, jasmonic acid (JA) production was found to be increased; whereas, brassinosteroid (BR) production, which is important for integrating salicylic acid (SA) pathway with jasmonic acid (JA) pathway, was suppressed (He et al. 2017; Pan et al. 2018). A recent study further showed that abscisic acid (ABA) could negatively regulate rice resistance to RBSDV infection (Xie et al., 2018).

In addition to above phytohormones, nitric oxide (NO) can also modulate plant and animal defenses against biotic and abiotic stresses (Schmidt and Walter 1994; Delledonne et al. 1998; Mur et al. 2006; Gaupels et al. 2011). NO can be produced through the nitrate/nitrite-dependent pathway that is known to be catalyzed by nitrate reductase (NR) (Gupta et al. 2011). In Arabidopsis, nitrate reductase1 and

\section{Springer Open}

() The Author(s). 2020 Open Access This article is licensed under a Creative Commons Attribution 4.0 International License, which permits use, sharing, adaptation, distribution and reproduction in any medium or format, as long as you give appropriate credit to the original author(s) and the source, provide a link to the Creative Commons licence, and indicate if changes were made. The images or other third party material in this article are included in the article's Creative Commons licence, unless indicated otherwise in a credit line to the material. If material is not included in the article's Creative Commons licence and your intended use is not permitted by statutory regulation or exceeds the permitted use, you will need to obtain permission directly from the copyright holder. To view a copy of this licence, visit http://creativecommons.org/licenses/by/4.0/. 
2 (AtNIA1/NIA2) genes were reported to be involved in the NR-dependent pathway (Lozano-Juste and León 2009; Lozano-Juste and León 2010). An earlier study showed that ABA could enhance NO production in plant guard cells to regulate stomatal closure (Neill et al. 2002). AtNIA1 and AtNIA2 mutants showed impaired stomatal closure due mainly to the altered expressions of core genes involved in ABA signaling, and the impaired stomatal closure could be restored by the applications of exogenous NO (Zhao et al. 2016). In addition, NO can be produced through $\mathrm{L}_{\text {-argin- }}$ ine-dependent pathway that is known to be catalyzed by mammalian NO synthase (NOS)-like enzyme (Crawford 2006; Besson-Bard et al. 2008; Simontacchi et al. 2015). In Arabidopsis, nitric oxide-associated1 (AtNOA1) gene was shown to be related to the ${ }_{\mathrm{L}}$-arginine- or NOS-dependent pathway (Sanz et al. 2014). NOS-dependent NO production was increased during the host response to Rhodococcus and Streptomyces, demonstrating the induction by host signals (Cohen and Yamasaki 2003; Johnson et al. 2008). It was reported that $\mathrm{NO}$ could regulate the interactions between plants and pathogens (Hong et al. 2008; Arasimowicz-Jelonek and Floryszak-Wieczorek 2014). For example, NO produced in tobacco could induce cell death to defend Pseudomonas syringae Pathovars (Mur et al. 2005). NO is also important for Arabidopsis resistance to Sclerotinia sclerotiorum (Perchepied et al. 2010). It was previously reported that NO could be produced during the interaction between plant and pathogen through the phytohormone-dependent signaling. Song and Goodman (2001) discovered that NO could regulate the SAinduced plant resistance against Tobacco mosaic virus (TMV) infection. To date, the function of NO in virus infection, especially in rice, remains largely unknown.

$S$-nitrosylation-mediated protein post-translational modification has been used to investigate the physiological functions of NO during animal and plant stress responses (Jaffrey and Snyder 2001; Lindermayr et al. 2005; Yun et al. 2011). Feechan et al. (2005) showed that the increase of AtGSNOR1 ( $S$-nitrosoglutathione reductase) activity could induce wheat resistance against wheat powdery mildew invasion. S-(hydroxymethyl)-glutathione dehydrogenase deletion mutants in Magnaporthe oryzae were sensitive to the NO application, and could produce more $S$-nitrosothiols (SNOs) than the wild type M. oryzae (Zhang et al. 2015). However, this NO-dependent $S$-nitrosylation has not been shown to be involved in rice resistance to virus infection.

Rice cv. Nipponbare is known to be susceptible to RBSDV infection (Lan et al. 2018), and rice cv. 15HPO187 was found to be resistant to RBSDV infection in our earlier field surveys. In this study, these two cultivars were used to study the role(s) of NO in rice resistance to RBSDV infection. We first compared the levels of endogenous $\mathrm{NO}$ in these two rice cultivars during RBSDV infection. The effects of NO-releasing reagents or $\mathrm{NO}$ scavengers on RBSDV infection in these two cultivars, were assessed. The possible cross-talks between $\mathrm{NO}$ and $\mathrm{SA}$, and the NOdependent $S$-nitrosylation were subsequently investigated. Because the endogenous NO level was reported to be suppressed in Arabidopsis and rice nia2 mutant plants (Wilkinson and Crawford 1991; Fan et al. 2007; Cao et al. 2008; Sun et al. 2016), the rice Osnia2 mutant plants were used to validate our pharmacological results on the function of $\mathrm{NO}$ in rice resistance to RBSDV infection. Our genetic results further indicated that NO might be a key regulator of rice resistance to RBSDV infection, at least partially, through a salicylic acid-dependent signaling.

\section{Results}

\section{HP0187 Plants Were Resistance to RBSDV Infection}

Nipponbare and 15HPO187 seedlings were inoculated with RBSDV viruliferous or non-viruliferous SBPHs. By 30 dpi, the RBSDV viruliferous SBPH-inoculated 15HPO187 plants showed mild leaf darkening and twisting symptoms; while, the RBSDV viruliferous SBPH-inoculated Nipponbare plants showed strong leaf darkening and twisting, and plant stunting (Figs. 1a, S1). Quantitative RT-PCR using RBSDV P10 ORF specific primers showed that RBSDV RNA accumulated similar in both RBSDV-inoculated 15HPO187 and Nipponbare plants at 10 and 20 dpi, but RBSDV RNA accumulated in 15HPO187 plants was much lower than in Nipponbare plants at 30 dpi (Fig. 1b). Consistently, approximately $85 \%$ of the RBSDV-inoculated Nipponbare plants showed virus symptoms, while only about $10 \%$ of the RBSDV-inoculated $15 \mathrm{HPO} 187$ plants showed virus symptoms (Fig. 1c).

\section{RBSDV Infection Altered Endogenous NO Metabolism}

To compare the productions of endogenous $\mathrm{NO}$ in the RBSDV-infected Nipponbare and 15HPO187 plants, stem cross sections were collected from the inoculated plants at 12 and $24 \mathrm{hpi}$, and stained with DAF-FM DA as previously described (Xie et al. 2013; Xie et al. 2014) followed by Confocal Microscopy. Results of the experiments showed that the fluorescence signal representing endogenous NO production in the RBSDV-infected 15HPO187 stems was significantly stronger than that in the Nipponbare stems, while there was no significant different in endogenous NO production between uninfected Nipponbare and 15HPO187 plants (Fig. 2a). To support this finding, we analyzed the time course of NR and NOS activities in the RBSDVinoculated 15HPO187 and Nipponbare plants. Agreed with the changes of $\mathrm{NO}$ production, the activities of NR and NOS were much higher in the RBSDV-infected 15HPO187 plants than that in the RBSDV-infected Nipponbare plants until 24 hpi, but the uninfected Nipponbare and 15HPO187 plants did not display such changes (Fig. 2b, c). qRT-PCR results showed that the relative expression level of OsNIA2 was significantly higher in the RBSDV-inoculated 15HPO187 plants than that in the Nipponbare plants at 12 
A

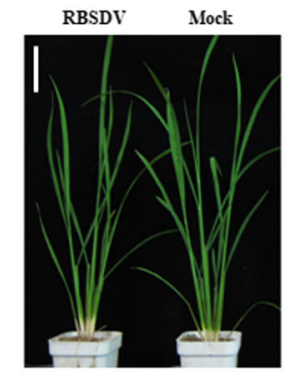

$15 \mathrm{HPO} 187$

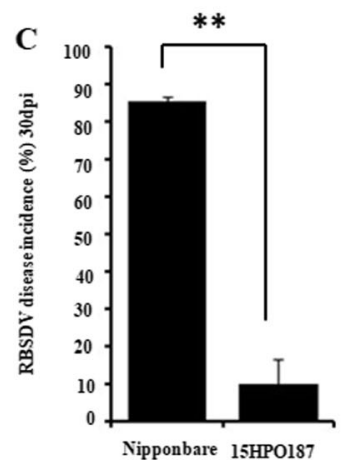

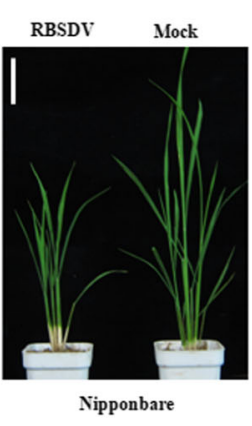

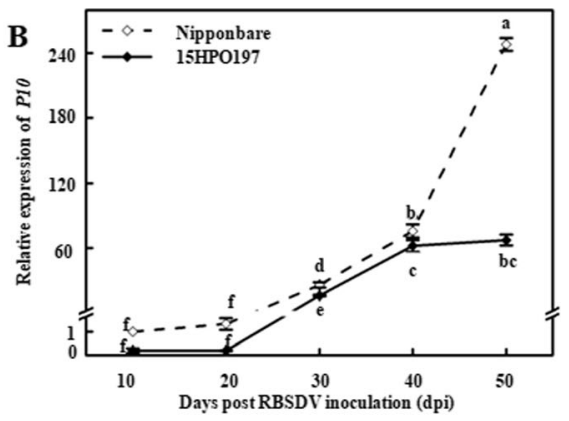

Fig. 1 The plant growth of Nipponbare and 15HPO187 challenged with RBSDV infection. a A mock- or RBSDV-inoculated Nipponbare (left) or 15 HPO187 (right) plants photographed at 30 dpi. b Time-course analysis of RBSDV P10 gene in the RBSDV-inoculated Nipponbare or 15 HPO187 plants at various dpi. Five plants were pooled together as one biological experiment for each time point for analysis. The data represented the means \pm SD of three biological replicates. Entire experiment repeated 3 times with similar results. c RBSDV disease incidence of the Nipponbare and $15 \mathrm{HPO} 187$ rice was determined at $30 \mathrm{dpi}$. 30 two-leaf stage rice seedlings of each cultivar were tests for disease incidence experiment. Scale bars $=5 \mathrm{~cm}$. Images are representative of three independent biological experiments. The data represented the means \pm SD of the three replicates. Different low case letters above the bars indicate the statistical differences between the treatments using the Duncan's multiple test, ${ }^{* *}, p<0.01$. Mock, plants were inoculated with non-viruliferous SBPHs; RBSDV, plants were inoculated with RBSDV viruliferous SBPHs

and 24 hpi (Fig. 2d). Similar result was also obtained for OsNOA1 (Fig. 2e).

\section{NO Production Was Affected by the Treatment of Exogenous NO after RBSDV Infection}

To further assess the role of endogenous $\mathrm{NO}$ in above process, Nipponbare seedlings were treated with the NOreleasing reagent SNP or GSNO followed by RBSDV inoculation. In the initial experiments, the seedlings were pretreated with 10,50 , or $100 \mu \mathrm{M} \mathrm{SNP}$, and the result showed that the pre-treatment of rice seedlings with SNP, especially at $50 \mu \mathrm{M} \mathrm{SNP}$, could significantly reduce RBSDV disease incidence (Fig. S2). Consequently in the later experiments, the rice seedlings were pre-treated with $50 \mu \mathrm{M}$ SNP or GSNO followed by RBSDV inoculation. By 30 dpi, RBSDV disease incidence of the SNP- or GSNO-treated plants were decreased significantly compared with the plants pretreated with water (Mock) (Fig. 3a). As expected, the pretreatment of rice seedlings with $50 \mu \mathrm{M}$ old SNP, a negative control of SNP, did not change RBSDV disease incidence significantly (Fig. 3b). When rice seedlings were pre-treated with cPTIO, a NO specific scavenger, the incidence of RBSDV disease was significantly increased.
To demonstrate the specificities of SNP and cPTIO on $\mathrm{NO}$ production in rice, we analyzed NO production in the stems of the SNP- or cPTIO-treated RBSDV-inoculated Nipponbare rice through DAF-2DA staining and Confocal Microscopy. Results of the experiments showed that the SNP-treated RBSDV-inoculated rice plants accumulated about 2.5 fold more NO compared with that in the watertreated RBSDV-inoculated plants (Figs. 3c, S3). In the same experiment, the cPTIO-treated RBSDV-inoculated rice plants showed a significant reduction of NO content compared with that in the water-treated RBSDV-inoculated plants. As expected, the level of NO in the old SNP-treated RBSDV-inoculated rice plants was similar to that in the water-treated RBSDV-inoculated rice plants. Combined with corresponding phenotypes in RBSDV disease incidence (Fig. 3a, b), these results indicate again that NO is a key regulator of rice resistance to RBSDV infection.

\section{OsICS1 and Stress-Responsive Gene Expression in Response to NO}

Since salicylic acid (SA), indoleacetic acid (IAA), jasmonic acid (JA) and abscisic acid (ABA) are important regulators of plant growth and development, in this study, 

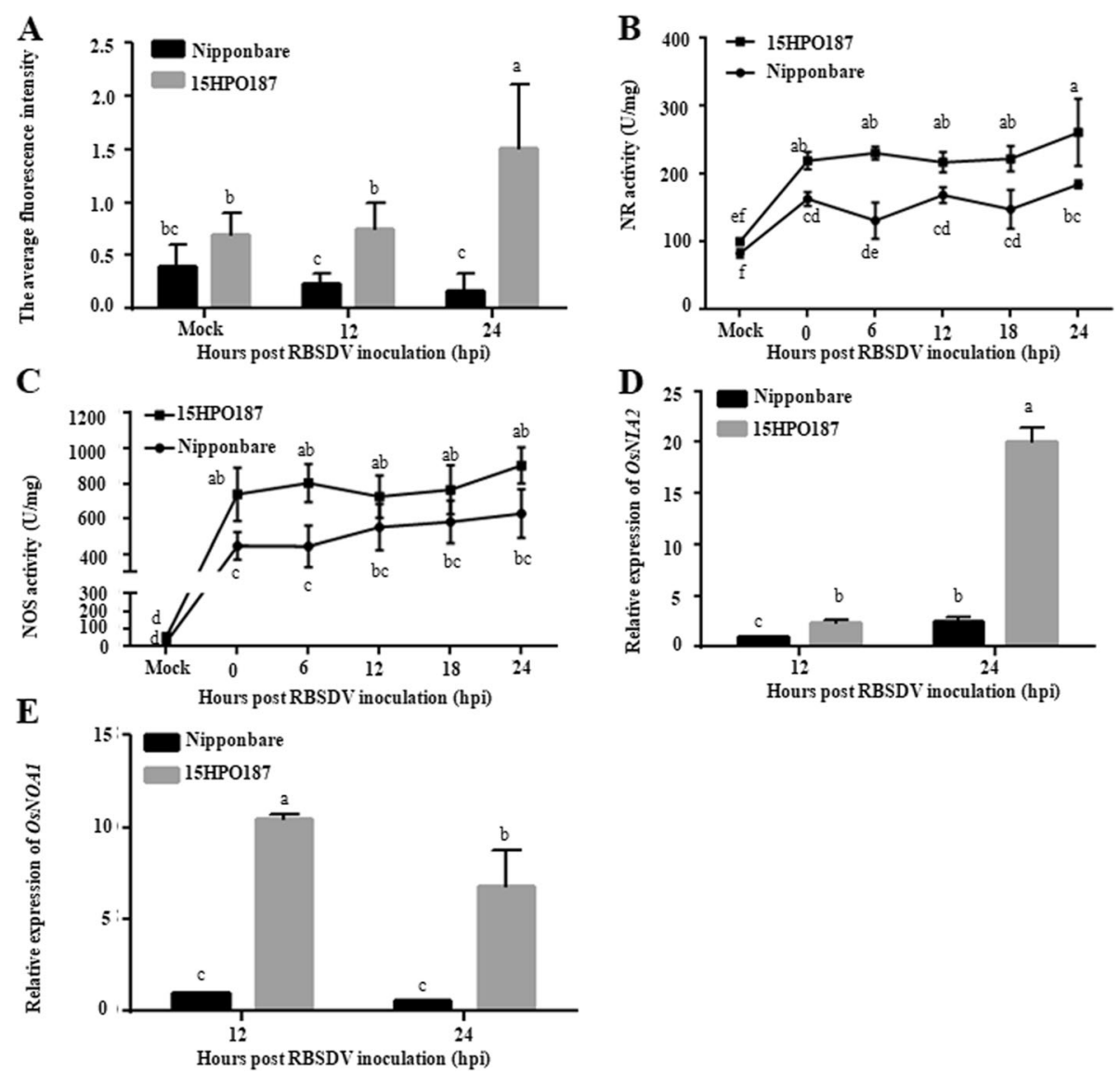

Fig. 2 Function of endogenous NO in RBSDV infection. a Endogenous NO accumulation in the RBSDV-inoculated Nipponbare or $15 \mathrm{HPO} 187$ plants at various hpi. Ten plants were analyzed as ten biological replicates. The data represented the means \pm SD of the ten replicates. Entire experiment repeated 3 times with similar results. $\mathbf{b}$ and $\mathbf{c}$ Activities of nitrate reductase (NR) and mammalian NO synthase (NOS)-like enzyme in the RBSDV-inoculated plants at various hpi. Ten plants were pooled together as one biological experiment. Images are representative of three independent biological experiments. The data represented the means \pm SD of the three replicates. $\mathbf{d}$ and e Expressions of OsNIA2 and OSNOA1 in the RBSDV-inoculated plants at various hpi. Five plants were pooled together as one biological experiment. The data represented the means \pm SD of the three biological replicates. Entire experiment repeated 3 times with similar results. Different low case letters above the bars indicate the statistical differences between the treatments using the Duncan's multiple test

we further analyzed the levels of these phytohormones in the RBSDV-infected and non-infected rice plants at $24 \mathrm{~h}$ after RBSDV infection. The results showed that SA production was affected by RBSDV infection (Fig. S4). Meanwhile, the Nipponbare rice seedlings supplemented with $500 \mu \mathrm{M}$ SA or BTH (a chemical analogues of SA) prior to RBSDV inoculation were also investigated. By $30 \mathrm{dpi}$, a significant reduction of RBSDV disease incidence was observed for the SA- or BTH-treated RBSDV-inoculated plants, compared with the water-treated RBSDV-inoculated plants (Fig. 4a). The result indicates that SA is also involved in the rice resistance to RBSDV infection.

To further investigate the relationship between NO and SA in rice, rice seedling plants were treated with SNP, old SNP or cPTIO followed by RBSDV inoculation. The expression levels of OsICS1 (encoding isochorismate synthase, a major enzyme involved in SA biosynthesis),
OsPR1b and OsWRKY 45 in these treated plants were analyzed at $6,12,18$, and $24 \mathrm{hpi}$, respectively. Results showed that the expression of OsICS1 in the SNPtreated plants was significantly up-regulated by 6 hpi compared with that in the water-treated plants. This upregulation was continued till $18 \mathrm{hpi}$ followed by a decrease at $24 \mathrm{hpi}$. Although the up-regulation of OsICS1 expression was significantly decreased at $24 \mathrm{hpi}$, it was still much higher than that in the water-treated plants (Fig. 4b). The expression of OsICS1 in the cPTIOtreated plants was not reduced until 24 hpi compared with that in the water-treated plants. It was, however, much lower than that in the SNP-treated plants at 6 through 24 hpi. Meanwhile, the plants treated with old SNP showed no significant change of OsICS1 expression compared with the water-treated plants. We also noticed that the expression of OsICS1 in the old SNP-treated 

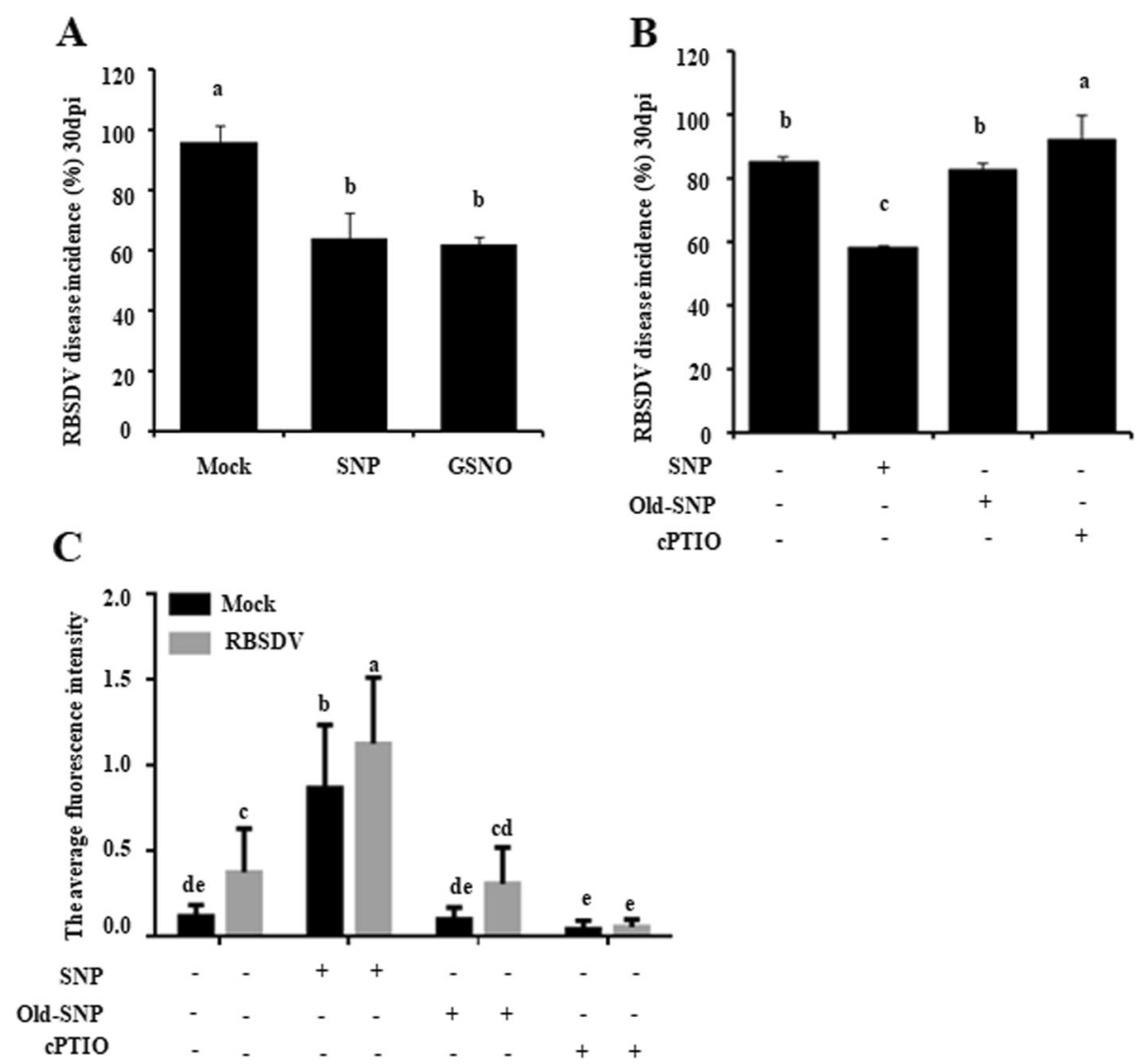

Fig. 3 Changes in Nipponbare rice resistance to RBSDV infection in response to NO-releasing reagents or NO scavenger. a RBSDV disease incidence of the $50 \mu \mathrm{M}$ SNP or GSNO pre-treated rice. RBSDV inoculation was carried out using RBSDV viruliferous or non-viruliferous SBPHs. Results were from three independent experiments with 30 plants per treatment. The data represented the means \pm SD of the three replicates. $\mathbf{b}$ RBSDV disease incidence of the $50 \mu \mathrm{M}$ SNP or old SNP, or $100 \mu \mathrm{M}$ CPTIO pre-treated Nipponbare rice. Plants pre-treated with water only were used as controls. RBSDV disease incidences were determined at $30 \mathrm{dpi}$. Results were from three independent experiments with 30 plants per treatment. The data represented the means \pm SD of the three replicates. c NO production in the stems of the SNP-, old SNP- or CPTIO pre-treated mock- or RBSDV-inoculated Nipponbare plants. Stem sections with about $3 \mathrm{~mm}$ thick, were stained with DAF-FM DA, and examined and imaged under a confocal laser scanning microscope. Then, the signal representing NO production in stems was captured and analyzed using the ZEN software. Ten plants were analyzed as ten biological replicates per treatment. The data represented the means \pm SD of the ten replicates. Entire experiment repeated 3 times with similar results. Different low case letters above the bars indicate the statistical differences between the treatments, by using the Duncan's multiple test

plants was much lower than that in the SNP-treated plants. The expression level of OsICS1 was also detected under these treatments without RBSDV infection. The result showed that the changes of OsICS1 in noninfected rice plants after various treatments were slight and lacked regularity (Fig. 4b).

The expressions of OsPR1b (6 through $24 \mathrm{hpi}$ ) and OsWRKY 45 (12 through 24 hpi) were significantly upregulated in the SNP-treated plants (Fig. 4c, d). On the other hand, the treatment of rice seedlings with cPTIO did not alter OsPR1b (except 12 hpi) or OsWRKY 45 (except $24 \mathrm{hpi}$ ) expression compared with that in the water-treated plants. When compared with the SNP-treated plants, the cPTIO-treatment suppressed OsPR1b (6 through $24 \mathrm{hpi}$ ) or OsWRKY 45 (12 through $24 \mathrm{hpi}$ ) expression. In the old SNP-treated plants, the expression of OsPR $1 b$ was induced at 12 and 18 hpi. These increases were, however, much lower than that in the SNP-treated plants. Similar tendencies were observed in the changes in OsWRKY 45 transcripts when old SNP was applied. The expression levels of OsPR1b and OsWRKY 45 were also detected under these treatments without RBSDV infection. The results showed that the changes of these two genes in non-infected rice plants after various treatments were slight and lacked regularity (Fig. $4 \mathrm{c}$ and d). These results indicate strongly that NO production in the RBSDV infected rice plants can regulate SA production and the stress-responsive genes.

\section{Profiles in Protein S-Nitrosylation}

To investigate whether NO can mediate protein $S$-nitrosylation during RBSDV infection in rice, we analyzed RBSDV-inoculated Nipponbare and 15HPO187 plants, and 


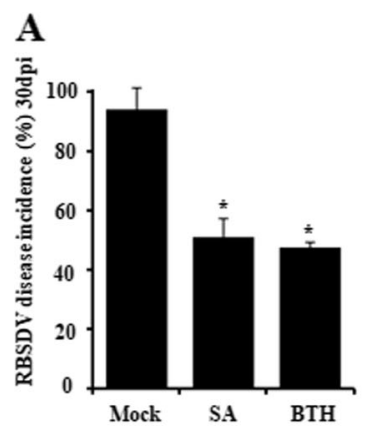

C

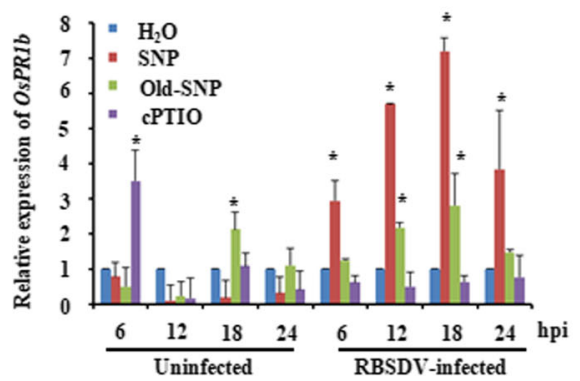

B

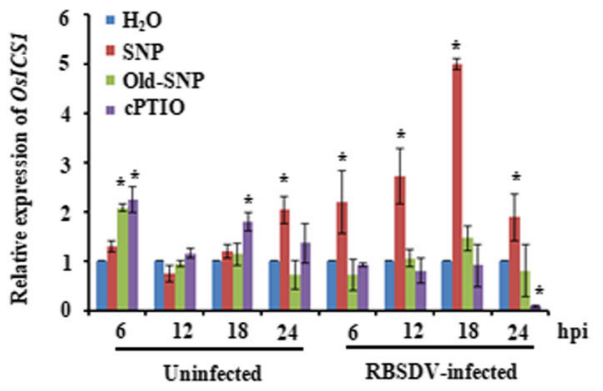

D

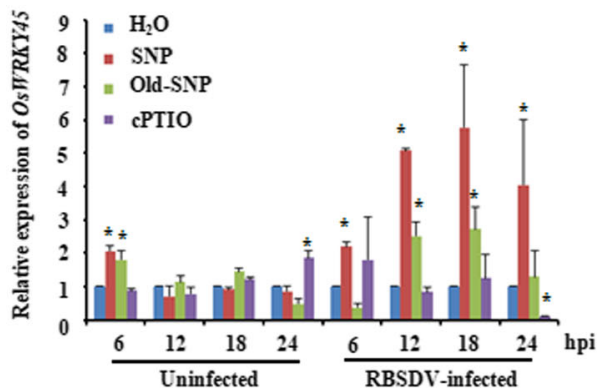

Fig. 4 Changes in SA and defense responsive genes. a RBSDV disease incidence of the $500 \mu \mathrm{M}$ SA- or $500 \mu \mathrm{M}$ BTH pre-treated Nipponbare rice. 30 two-leaf stage rice seedlings of each cultivar were tests for disease incidence experiment. Images are representative of three independent biological experiments. The data represented the means \pm SD of the three replicates. $\mathbf{b}$ to $\mathbf{d}$ Expressions of OsICS1, OsPR1b and OsWRKY 45 in the SNP-, old SNPor CPTIO-treated RBSDV-inoculated plants determined by qRT-PCR. Expressions of OsUBC and OsActin1 in the rice plants were used as internal controls. The expression levels of OSICS1, OSPR16 and OSWRKY 45 in the water-treated RBSDV-inoculated plants were set as 1.0. Five plants were pooled together as one biological experiment. The data represented the means \pm SD of the three biological replicates. Entire experiment repeated 3 times with similar results. Statistical differences between treatments in each time point were determined by the Duncan's multiple test, $p<0.05$

compared them with the mock-inoculated plants using a modified biotin switch assay. Results showed that the level of protein $S$-nitrosylation was significantly increased in the RBSDV-inoculated Nipponbare and $15 \mathrm{HPO} 187$ plants (Fig. 5a and e). In this study, we also analyzed the SNP-, old SNP- or cPTIO-treated and RBSDV- or mock-inoculated Nipponbare plants. The results showed that the SNP treatment did intensify protein $S$-nitrosylation during RBSDV infection. When cPTIO or old SNP was individually used, the level of protein $S$-nitrosylation was not altered significantly, compared with that in the water-treated RBSDVinoculated plants (Fig. 5b and f). This result indicates that NO produced during RBSDV infection in rice can $S$-nitrosylate proteins at post-translational level.

\section{Genetic Evidence Supported the Finding that NO Enhances Rice Resistance against RBSDV}

AtNIA1 and AtNIA2 were reported to control NO production in Arabidopsis, and play important roles in Arabidopsis resistance to pathogen invasions (Lozano-Juste and León 2009; Lozano-Juste and León 2010). In this study, we analyzed wild type (WT) rice cv. Dongjing and its Osnia2 mutant plants for their responses to RBSDV infection. Results of confocal microscopy shown in Fig. 6a indicated that the level of NO in the infected Osnia 2 mutant plants (18 hpi) was much lower than that in the WT plants; while, when SNP was administrated, NO level was restored, approximately to the similar levels in the WT. By 30 dpi inoculation, the disease incidence of the mutant plants was significantly higher than that shown in the WT plants, which was decreased obviously when SNP was used. We also pretreated SA on Osnia2, and the results showed that the phenotype of pretreated mutant could be recovered to the similar level of WT. And the amount of endogenous SA was decreased in Osnia2 mutant compared with the WT, while SA treatment could recover the endogenous SA accumulation, similar to that level in WT (Fig. 6b). These genetic findings thus support the above results, indicating that NO plays an important role in rice resistance to RBSDV infection through the SA pathway.

\section{Discussion}

Although multiple RBSDV resistant or tolerant rice cultivars have been utilized in rice production, the mechanism(s) controlling this resistance or tolerance are still 

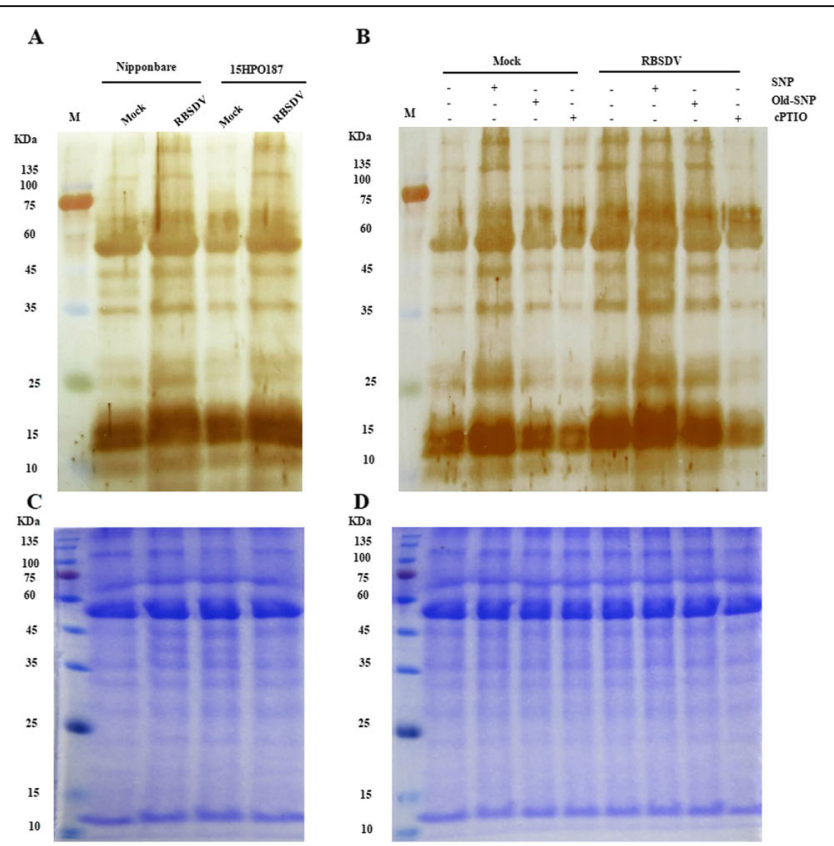

$\mathbf{E}$

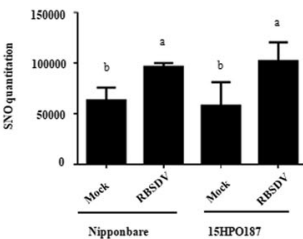

$\mathbf{F}$

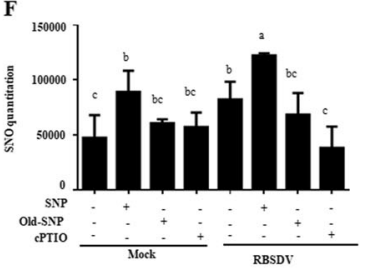

Fig. 5 NO-dependent protein S-nitrosylation. a Total protein was isolated from the mock- or RBSDV-inoculated Nipponbare or $15 \mathrm{HPO} 187$ plants. The isolated protein samples were analyzed by a modified biotin switch method followed by western blot assay using a biotin specific antibody. Lanes with darker labeling signal indicate stronger protein S-nitrosylation. b Total protein was isolated from the SNP-, old SNP- or CPTIO-treated and mock- or RBSDV-inoculated plants and analyzed as described in (a). Numbers on the left slide of the gels are the size of protein markers. $\mathbf{c}$ and $\mathbf{d}$ Images of gels stained with Coomassie Brilliant Blue, and used to show equal protein loadings. Images are representative of experiments repeated at least three separate times. The blot was quantified using ImageJ software (http://rsbweb.nih.gov/ij/). The data represented the means \pm SD of the three replicates. M, protein marker. All the experiment were repeated 3 times and representative results are shown

not fully elucidated. In our previous studies, we found several RBSDV resistant rice cultivars, including cv. 15HPO187. This finding promoted us to identify the key factor(s) regulating rice RBSDV resistance. In our test, the increase of $\mathrm{NO}$ level in the Nipponbare rice plants by RBSDV-infection supports the conclusion that NO production in plants can be induced upon pathogen invasion (Zou et al. 2018). Compared to the NO production in the Nipponbare plants (a sensitive cultivar) with that in the 15 HPO187 plants (a resistant cultivar), we have found that RBSDV infection in the $15 \mathrm{HPO} 187$ plants produced much more NO than that in the Nipponbare plants (Figs. 1, 2a). Because NO is known to be catalyzed by nitrate reductase (NR) or mammalian NO synthase (NOS)-like enzyme (Besson-Bard et al. 2008; Simontacchi et al. 2015), we analyzed the activities of these two enzymatic activities in RBSDVinfected Nipponbare and $15 \mathrm{HPO} 187$ plants. Consistent with the NO results shown above, the activities of these two enzymes were significantly up-regulated in the infected plants, especially in the 15 HPO187 plants (Fig. 2b, c). We speculate that the higher NOS and NR activities in the RBSDV infected 15HPO187 plants caused more NO production, and more NO in the plants caused a higher resistance to RBSDV infection.

Multiple NO production inducers and scavengers are now available for $\mathrm{NO}$ function studies. For example, sodium nitroprusside (SNP) is a commonly used NO-releasing compound or NO donor in many laboratories (Lindermayr et al. 2005; Zhao et al. 2018). 2-(4-Carboxyphenyl)-4, 4, 5, 5tetramethylimidazoline-1-oxyl-3-oxide (cPTIO) is a commonly used NO specific scavenger in many studies (Liu et al. 2015; Deng et al. 2016). To validate the role of endogenous NO in rice resistance to RBSDV infection, we treated Nipponbare rice seedlings with two NO-releasing reagents SNP and GSNO, and then inoculated plants with RBSDV. Result of the initial experiment showed that rice plants pre-treated with $50 \mu \mathrm{M}$ SNP showed much lower RBSDV disease incidence than the plants pre-treated with 10 or $100 \mu \mathrm{M}$ SNP (Fig. S2). Consequently, in all later experiments, both NO-releasing reagents were diluted to $50 \mu \mathrm{M}$ prior to use. As expected, the plants pre-treated with NOreleasing reagent showed a significant reduction of RBSDV disease incidence (Fig. 3a, b). To further confirm this finding, we pre-treated rice seedlings with a NO scavenger (cPTIO) followed by RBSDV inoculation. Result of this experiment showed that the NO production in the rice plants pretreated with $\mathrm{CPTIO}$ was significantly suppressed, leading to a significant increase of RBSDV disease incidence in the plants (Fig. 3c, d). Therefore, we suggested that NO is an important regulator of rice resistance to RBSDV infection.

Song and Goodman (2001) reported that the size of TMV-induced local lesions in tobacco leaves was reduced 

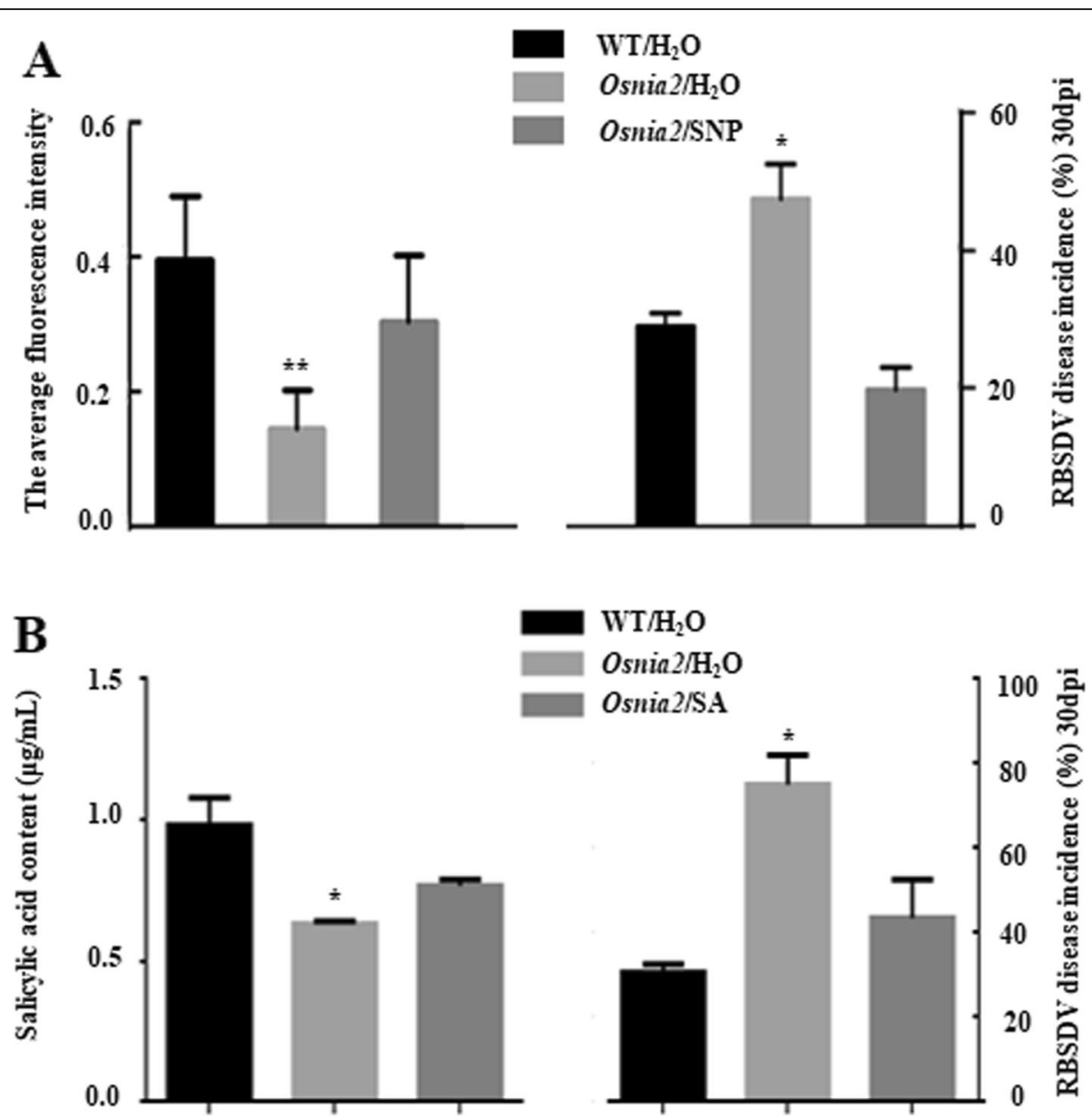

Fig. 6 RBSDV disease incidence and NO production in rice cv. Dongjing (WT) and Osnia2 mutant plants. a Left. NO production in the SNP-treated RBSDV-inoculated Osnia2 mutant plants and RBSDV-inoculated Dongjing and Osnia2 mutant. NO production analysis was assessed as described in Fig. 3. Ten plants were analyzed as ten biological replicates per treatment. The data represented the means \pm SD of the ten replicates. Entire experiment repeated 3 times with similar results. Right. Dongjing and Osnia2 mutant rice plants were pre-treated with SNP followed by RBSDV inoculation. Disease incidences of Dongjing and Osnia2 mutant rice were determined from three independent experiments with 30 plants per treatment. The data represented the means \pm SD of the three replicates. $\mathbf{b}$ Left. The amount of endogenous SA in the SA-treated RBSDVinoculated Osnia2 mutant plants and RBSDV-inoculated Dongjing and Osnia2 mutant. The data represented the means \pm SD of the three replicates. Entire experiment repeated 3 times with similar results. Right. Dongjing and Osnia2 mutant rice plants were pre-treated with SA followed by RBSDV inoculation. Disease incidences of Dongjing and Osnia2 mutant rice were determined from two independent experiments with 30 plants per treatment. The data represented the means \pm SD of the two replicates. Statistical differences between the treatments were determined by the Duncan's multiple test, $p<0.01$ or $p<0.05$

after the NO induction, and the bioactivity of $\mathrm{NO}$ was dependent on the function of salicylic acid (SA) generated through the systemic acquired resistance (SAR) signaling pathway. Phytohormones were also known to regulate plant defense responses to biotic and/or abiotic stresses (Klessig et al. 2000; Freschi 2013; Ji et al. 2016; Qi et al. 2016). This leads us to investigate the interaction between NO and SA using SNP-, or CPTIO-treated rice plants. Results of the experiment showed that, similar to the response of NO, the production of SA in the SNP-treated RBSDV-inoculated rice plants was significantly induced while SA production in the CPTIO-treated RBSDV-inoculated plants was obviously suppressed (Fig. 4c). Based on these findings, we conclude that RBSDV infection in rice increases $\mathrm{NO}$ and SA production, and higher productions of $\mathrm{NO}$ and SA in the $15 \mathrm{HPO} 187$ plants might result in a resistance to RBSDV infection.

Previous studies have indicated that plant $P R 1$ gene is involved in the SA signaling (Klessig et al. 2000; Šašek et al. 2014). Transcription factor OsWRKY45 was also reported to be responsive to SA or BTH during rice defense against rice blast and bacterial blight pathogen infections (Shimono et al. 2007; Shimono et al. 2012; Li et al. 2014). In addition, OsICS1 was shown as a key gene for SA biosynthesis (Choi et al. 2015). To further validate SA induction, we treated rice seedlings with SNP or CPTIO prior to 
RBSDV inoculation and then analyzed the expressions of two SA responsive genes OsPR $1 b$ and OsWRKY 45, and OsICS1 transcript. As expected, the SNP-treated RBSDVinoculated plants showed up-regulated expressions of these three genes, especially at $18 \mathrm{hpi}$ (Fig. $4 \mathrm{~d}$ to f). In contrast, the cPTIO-treated RBSDV inoculated plants showed significantly reduced expressions of OsICS1, OsPR $1 b$ and OsWRKY 45 compared with that in the water-treated RBSDV-inoculated plants. In addition, plants pre-treated with SA or BTH showed much lower RBSDV disease incidences than the water-treated RBSDV-inoculated control plants (Fig. 4b). Many research laboratories have used protein $S$-nitrosylation assay to investigate the functions of NO in plant responses to biotic and abiotic stresses (Jaffrey and Snyder 2001; Lindermayr et al. 2005; Yun et al. 2011). In this study, our protein $S$-nitrosylation assay showed that the induction of NO production (Fig. 2a) in the SNPtreated mock-inoculated or RBSDV-inoculated plants did increase protein $S$-nitrosylation (Fig. 5). As expected, the increase of protein $S$-nitrosylation was not observed in the cPTIO-treated mock-inoculated or RBSDV-inoculated plants, due mainly to the lack of $\mathrm{NO}$ production. Combined with the corresponding phenotypes (Fig. 3), our results strongly suggested that NO-targeted $S$-nitrosylation might be involved in rice resistance to RBSDV infection. Certainly, the direct target of $S$-nitrosylation during this process should be fully elucidated in the near future.

It was reported that Arabidopsis Atnia1/2 mutant plants had lower NR activity than the WT plants (Wilkinson and Crawford 1993). To provide genetic evidence showing that rice plants with less endogenous NO were more susceptible to RBSDV infection, we challenged our Osnia2 mutant rice seedlings with RBSDV, and compared them with the WT parental plants. Results presented in Fig. 6 showed that the Osnia2 mutant plants had much lower NO content than that in the WT plants challenged with RBSDV. Consistently, the RBSDV disease incidence of the Osnia2 mutant rice was much higher than that of the WT parental rice (Fig. 6). Above responses could be obviously abolished when exogenously applied SNP was used. This genetic result further supports our conclusion that NO has a key role in rice resistance to RBSDV infection.

\section{Conclusions}

Taken together, we propose a working model for the NOdependent rice resistance to RBSDV infection (Fig. 7). RBSDV infection in rice causes an early NO burst. The accumulated NO might act as an inducer to induce SA production. It was reported that the SA-dependent signaling can be divided into two branches: the OsNPR1 transcription factor dependent branch and the OsWRKY45 transcription factor dependent branch, as reported previously (Sugano et al. 2010; Nakayama et al. 2013; Takatsuji 2014). NPR1 monomers are synthesized in cytoplasm and then translocated into nucleus to bind TGACG motifbinding factor (TGA1), a transcription factor controlling the expressions of many downstream defense genes, to form NPR1-TGA1 complexes to trigger the expressions of specific R genes as reported (Lindermayr et al. 2010). Previous genetic studies have shown that OsWRKY45 is involved in the SA signaling pathway and is responsible for the activation of rice defense genes against Magnaporthe oryzae and Xanthomonas oryzae pv oryzae infection (Nakayama et al. 2013; Bakshi and Oelmüller 2014). In this study, SA induced the expressions of OsWRKY45 and $O s P R 1 b$, which is involved in inhibition of virus infections. However, whether OsWRKY45 and OsPR1b inhibit the virus infection is still unknown until a genetic analysis is taken. We consider that our study improves our current understanding on the interaction between rice and RBSDV, and possibly other rice-infecting viruses.

\section{Methods \\ Chemicals}

Unless otherwise specified, all chemicals used in this study were purchased from Sigma-Aldrich (Sigma-Aldrich, St Louis, MO, USA). In this study, SNP and GSNO were used as NO-releasing reagents, diluted to $50 \mu \mathrm{M}$ in water, and applied to soil in pots $(9 \mathrm{~cm}$ in diameter and $14 \mathrm{~cm}$ tall, $25 \mathrm{~mL} /$ pot) with rice seedlings (Parani et al., 2004). At $12 \mathrm{~h}$ post SNP or GSNO application, the rice seedlings were inoculated with RBSDV viruliferous small brown planthopper (SBPH). The old SNP solution was produced by placing the SNP solution inside test tubes and stored them under the light for more than 10 days to exhaust NO. The old SNP solution was obtained as a negative control by maintaining a $50 \mu \mathrm{M}$ SNP solution for at least $2 \mathrm{~d}$ in the light in an open tube to eliminate $\mathrm{NO}$ as described (Tossi et al. 2009; Han et al. 2014). 2-(4-carboxyphenyl)-4, 4, 5, 5-tetramethylimidazoline-1-oxyl-3-oxide (cPTIO), a NO specific scavenger, was diluted to $100 \mu \mathrm{M}$ in water prior to use (Parani et al., 2004; Kong et al., 2012). Salicylic acid (SA) and 2, 1, 3-benzothiadiazole (BTH) were purchased from MDBio (MDBio Inc., Taiwan, China), and diluted to $500 \mu \mathrm{M}$ in water (SA was diluted by $1 \mathrm{~mL}$ ethanol first, then used water to constant volume), respectively. These reagents were applied individually to rice seedlings as described for SNP and GSNO above.

\section{Plant Growth and Virus Inoculation}

For the experiments described in Figs. 1, 2, 3, 4 and 5, RBSDV viruliferous or non-viruliferous SBPH-inoculated rice seedlings cv. Nipponbare (a susceptible cultivar to RBSDV) and/ or $15 \mathrm{HPO} 187$ (a resistance cultivar to RBSDV) were used. For the experiment described in Fig. 6, seedlings of rice cv. Dongjing and its Osnia2 mutant were used (Sun et al. 2016).

SBPH nymphs were allowed to feed on the RBSDVinfected rice plants for $72 \mathrm{~h}$ as previously described (Zhou 


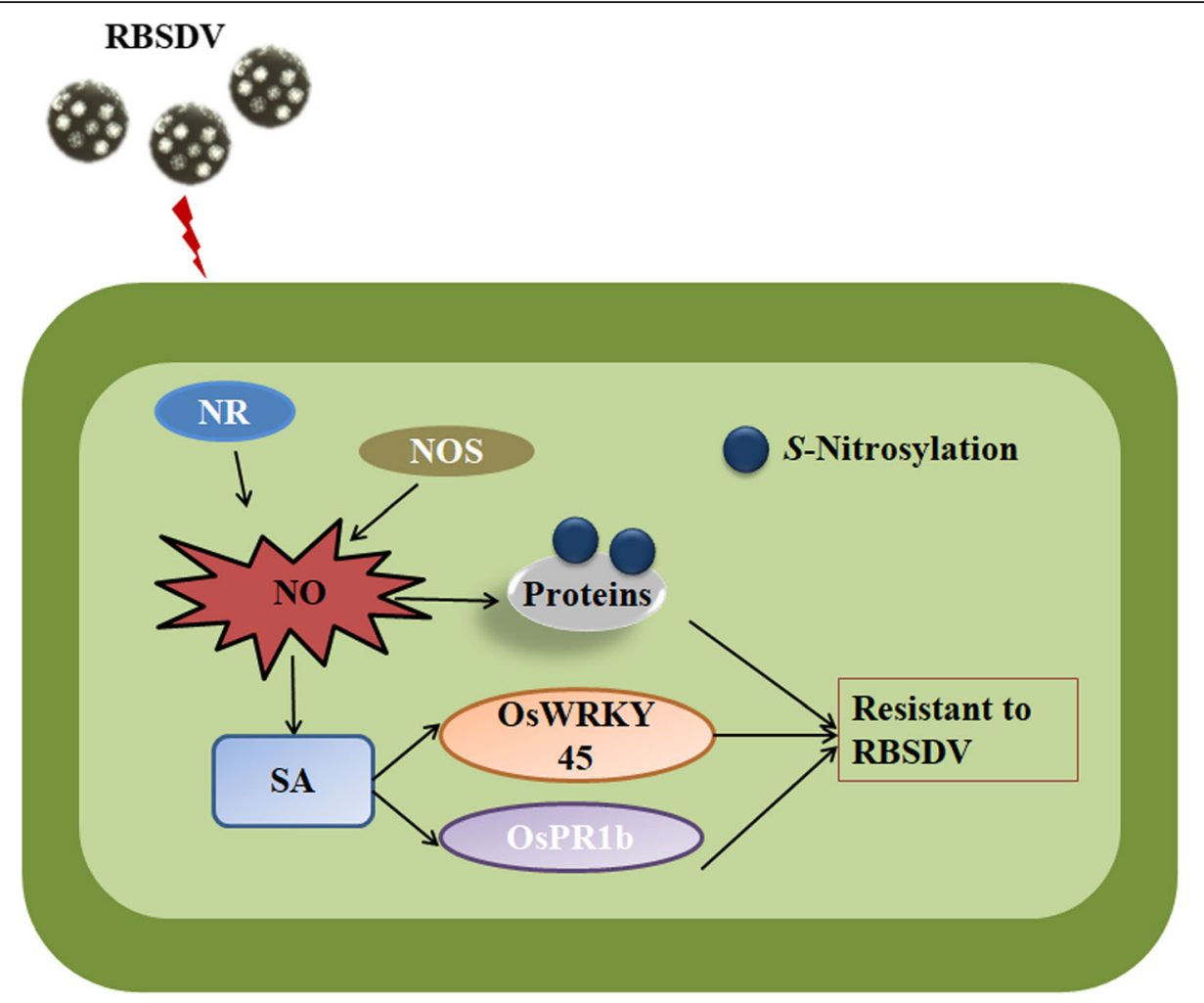

Fig. 7 A working model for NO-dependent rice resistance to RBSDV infection. RBSDV infection in rice plants causes an early NO burst. The accumulated endogenous NO catalyzed by NR and NOS activities, acts as an inducer to trigger SA production. The accumulated SA up-regulates the expressions SA responsive host defense genes, thus leading to rice resistant to RBSDV

et al. 2010). The nymphs were transferred onto healthy rice seedlings cv. Wuyujing No. 3 and allowed to feed on them for another $10-12$ days at $25^{\circ} \mathrm{C}$. The percentage of viruliferous SBPH was then determined by a dot enzymelinked immunosorbent assay (Dot-ELISA) as described (Zhou et al., 2004). For virus inoculation, 30 two-leaf stage rice seedlings were randomly selected and each seedling was inoculated with three viruliferous SBPHs for 3 days as described (Zhou et al. 2011). Seedlings inoculated with non-viruliferous SBPHs were used as controls. Leaf tissues were sampled from the inoculated plants at various hours post SBPH inoculation (hpi), or various days post SBPH inoculation (dpi). The collected leaf tissues were immediately frozen in liquid nitrogen and stored at $-80^{\circ} \mathrm{C}$ till use.

\section{Analysis of NOS or NR Activity}

The NOS or NR activity was determined following the previous method (Zhao et al. 2009). For NOS activity, $200 \mu \mathrm{L}$ of protein extract in the reaction mixture (100 mM PBS, $\mathrm{pH}$ 7.0, containing $1 \mathrm{mM} \mathrm{L}$-arginine, $2 \mathrm{mM} \mathrm{MgCl}_{2}, 0.3 \mathrm{mM} \mathrm{CaCl}_{2}$, $4 \mu \mathrm{M}$ tetrahydrobiopterin, $1 \mu \mathrm{M}$ flavin adenine dinucleotide, $1 \mu \mathrm{M}$ flavin mononucleotide, $0.2 \mathrm{mM}$ DL-dithiothreitol, 0.2 $\mathrm{mM} \mathrm{NADPH}$ ) was detected spectrophotometrically at 340 $\mathrm{nm}$. For NR activity, the produced nitrite was determined spectrophotometrically at $540 \mathrm{~nm}$ by the addition of $1 \mathrm{ml}$ of $1 \%(\mathrm{w} / \mathrm{v})$ sulfanilamide in $3 \mathrm{M} \mathrm{HCl}$ together with $1 \mathrm{ml}$ of $0.02 \%(\mathrm{v} / \mathrm{v}) \mathrm{N}-(1-$ naphthyl)- ethylenediamine.

\section{Quantification of Endogenous NO in Rice Stems}

The samples were collected at $18 \mathrm{~h}$ after RBSDV infection. Cross sections ( $3 \mathrm{~mm}$ thick) were cut from stems of viruliferous or non-viruliferous $\mathrm{SBPH}$-inoculated rice plants, infiltrated with a NO fluorescent probe $(10 \mu \mathrm{M}$ 4-amino-5-methyl-amino-2', $7^{\prime}$-di-fluorofluorescein diacetate [DAF-FM DA]) diluted in a $20 \mathrm{mM}$ Hepes- $\mathrm{NaOH}$ buffer, $\mathrm{pH}$ 7.2, followed by $15 \mathrm{~min}$ incubation in the dark (Balcerczyk et al. 2005; Qi et al. 2017).

After thorough rinse in the Hepes- $\mathrm{NaOH}$ buffer, the sections were examined, imaged, and processed using a Zeiss LSM 710 confocal laser scanning microscope equipped with a ZEN software (Carl Zeiss, Oberkochen, Germany). The excitation wavelength was set at $488 \mathrm{~nm}$ and the emission wavelength was set at $500-530 \mathrm{~nm}$. More than 10 rice plants were analyzed for each treatment.

\section{Quantification of Endogenous SA in Tissue Samples}

The assay was determined following the previous method (Novák and Floková 2018). Rice leaf samples (500 mg each) were collected from the assayed plants at $24 \mathrm{hpi}$, 
ground individually in liquid nitrogen, and then homogenized in $10 \mathrm{~mL}$ extraction buffer of isopropanol/H2O/ hydrochloric acid (200:100:0.2). The crude leaf extracts were shaked for $12 \mathrm{~h}$ followed by adding $15 \mathrm{~mL}$ dichloromethane. The organic phase evaporated in vacuo to dryness, which was dissolved in $400 \mu \mathrm{l} 50 \%$ methanol. The samples were filter with $0.22 \mu \mathrm{m}$ organic filter membrane, then were taken for analysis by HPLC-MS (1260 FLD Serial No.DEAB001256).

\section{Total RNA Isolation and Quantitative Reverse Transcription Polymerase Chain Reaction (qRT-PCR)}

Total RNA was isolated from rice leaf samples $(100 \mathrm{mg}$ tissue per sample) using Trizol reagent (Invitrogen, Gaithersburg, MD, USA). Concentration of total RNA in each sample was determined using a NanoDrop 2000 Spectrophotometer (Thermo Fisher Scientific, Wilmington, DE, USA). cDNA was synthesized using one $\mu \mathrm{g}$ total RNA per $20 \mu \mathrm{L}$ reaction using the PrimeScript ${ }^{\text {th }}$ RT reagent Kit with a gDNA Eraser (Takara, Dalian, China). qPCR was then performed using the SsoFast EvaGreen ${ }^{\circ}$ Supermix (Bio-Rad) on a Bio-Rad iQ5 qRT-PCR system. The expression levels of OsUBC and OsActin1 were determined and used as internal controls as previously reported (Fang et al. 2015; Lu et al. 2016). qPCR primers specific for RBSDV P10, OsNOA1, OsNIA2, OsPR1b, OsWRKY45 or OsICS1 are listed in the Supplementary Table 1. The qRT-PCR results were calculated using the $2^{-\Delta \Delta \mathrm{Ct}}$ method reported previously (Livak and Schmittgen 2001).

\section{Immunoblot Assay of S-Nitrosylated Proteins}

Assays of $S$-nitrosylated proteins were done as described previously (Jaffrey and Snyder 2001; Forrester et al. 2009; Qi et al. 2017). Total protein was isolated from the collected tissues at 24hpi and the $S$-nitrosylated biotinlabeled proteins were separated in 12\% SDS-PAGE gels under the non-reducing condition. The protein bands were blotted onto polyvinylidene difluoride (PVDF) membranes followed by protein detection using an antibiotin antibody (Abcam antibodies, Cambridge, UK). The blot was quantified using Image software (http:// rsbweb.nih.gov/ij/). Protein loadings were estimated through Coomassie Brilliant Blue staining.

\section{Statistical Analysis}

All the experiments conducted in this study were done in triplicate. Results of the experiments were presented as the means of the three independent experiments \pm standard deviation (SD). Statistical analyses were performed using the SPSS 18.0 software (Armonk, USA) and the Duncan's multiple tests. Differences at $p<0.05$ were considered to be significant.

\section{Supplementary information}

Supplementary information accompanies this paper at https://doi.org/10. 1186/s12284-020-00382-8.

Additional file 1: Fig. S1. The phenotype of RBSDV-inoculated Nipponbare and 15HPO187. Representative three plants of each cultivar were shown. Scale bars $=5 \mathrm{~cm}$.

Additional file 2: Fig. S2. Disease incidence of RBSDV-inoculated Nipponbare pre-treated with different concentrations of SNP. Nipponbare plants were pre-treated with different concentrations of SNP for $12 \mathrm{~h}$ followed by RBSDV inoculation using viruliferous SBPHs. 30 two-leaf stage rice seedlings of each cultivar were tests for disease incidence experiment. Images are representative of three independent biological experiments. The data represented the means \pm SD of the three replicates.

Additional file 3: Fig. S3. NO production in the stems by different treatments in mock- (left column) or RBSDV-inoculated (right column) Nipponbare plants. NO production in the stems of the SNP-, old SNP- or CPTIO pre-treated mock- (left column) or RBSDV-inoculated (right column) Nipponbare plants. Stem sections were about $3 \mathrm{~mm}$ thick, stained with DAF-FM DA, and examined and imaged under a confocal laser scanning microscope. Up and right corner inserts are bright filed images of the stem sections. Scale bars $=200 \mu \mathrm{M}$. Images are representative of biological replicates from experiments repeated at least three times.

Additional file 4: Fig. S4. Concentrations of phytohormones in RBSDVinfected (RBSDV) or Non-infected (Mock) Nipponbare plants. Accumulations of three different phytohormones in the RBSDV-infected or noninfected rice plants were determined by high efficiency liquid chromatography method (ACQUITY UPLC Xevo TQ, Waters, USA). 100 mg plant tissues were used as one biological experiment. Images are representative of three independent biological experiments. The data represented the means \pm SD of the three replicates.

Additional file 5: Table S1. Primers used for quantitative reverse transcription polymerase chain reaction (qRT-PCR).

\section{Abbreviations}

RBSDV: Rice black-streaked dwarf virus; NO: Nitric oxide; SNP: Sodium nitroprusside; GSNO: Nitrosoglutathione; CPTIO: 2-(4-carboxyphenyl)-4, 4, 5, 5tetramethylimidazoline-1-oxyl-3-oxide; NOS: NO synthase; NR: Nitrate reductase; SA: Salicylic acid; BTH: 2, 1, 3-benzothiadiazole

\section{Acknowledgements}

The authors are grateful to Dr. Xinshun Ding (Nobel foundation, USA, retired) for providing great advices for this manuscript.

\section{Authors' Contributions}

$T Z, W S, Y Z$, and JC conceived the project and designed the experiments; RL and $Z L$ carried out the experiments with assistance from $Y S, J S, X L$ and $Y Z$; $\mathrm{RL}$ and $\mathrm{ZL}$ analyzed the results with assistance from $F S$ and $S L ; Y Z$ provided the plant materials; $R L$ and $Z L$ wrote the manuscript. The author(s) read and approved the final manuscript.

\section{Funding}

This work was supported by the National Natural Science Foundation of China (31761143012, 31601704), Six talent peaks project of Jiangsu Province (NY-056), 333 high level talent training project of Jiangsu Province (BRA2018081)

\section{Availability of Data and Materials}

All data supporting the conclusions of this article are provided within the article (and its Additional files).

Ethics Approval and Consent to Participate Not applicable.

Consent for Publication

Not applicable.

Competing Interests

The authors declare that they have no competing interests. 


\section{Author details}

Key Laboratory of Food Quality and Safety, Institute of Plant Protection, Jiangsu Academy of Agricultural Sciences, Nanjing 210014, Jiangsu Province, China. ${ }^{2}$ College of Life Sciences, Laboratory Center of Life Sciences, Nanjing Agricultural University, Nanjing 210095, China. ${ }^{3}$ School of the Environment and Safety Engineering, Jiangsu University, Zhenjiang 212013, Jiangsu Province, China. ${ }^{4}$ College of Resources and Environmental Sciences, Nanjing Agricultural University, Nanjing 210095, China

\section{Received: 28 October 2019 Accepted: 12 March 2020} Published online: 14 April 2020

\section{References}

Arasimowicz-Jelonek M, Floryszak-Wieczorek J (2014) Nitric oxide:an effective weapon of the plant or the pathogen? Mol Plant Pathol 15:406-416

Bai FW, Jian Y, Qu ZC, Zhang HW, Xu J, Ye MM, Shen DL (2002) Phylogenetic analysis reveals that a dwarfing disease on different cereal crops in China is due to rice black streaked dwarf virus (RBSDV). Virus Genes 25:201-206

Bakshi M, Oelmüller R (2014) WRKY transcription factors: Jack of many trades in plants. Plant Signal Behav 9:e27700

Balcerczyk A, Soszynski M, Bartosz G (2005) On the specificity of 4-amino-5methylamino-2',7'-difluorofluorescein as a probe for nitric oxide. Free Radic Biol Med 39:327-335

Besson-Bard A, Pugin A, Wendehenne D (2008) New insights into nitric oxide signaling in plants. Ann Review Plant Biol 59:21-39

Cao Y, Fan XR, Sun SB, Xu GH, Hu J, Shen QR (2008) Effect of nitrate on activities and transcript levels of nitrate reductase and glutamine synthetase in rice. Pedosphere 18:664-673

Chen S, Zhang Q (2005) Advance in researches on rice black--streaked dwarf disease and maize rough dwarf disease in China. J Plant Protection 32:97-103

Choi C, Hwang SH, Fang IR, Kwon SI, Park SR, Ahn I, Kim JB, Hwang DJ (2015) Molecular characterization of Oryza sativa WRKY6., which binds to W-box-like element 1 of the Oryza sativa pathogenesis-related (PR) 10a promoter and confers reduced susceptibility to pathogens. New Phytol 208:846-859

Cohen MF, Yamasaki H (2003) Involvement of nitric oxide synthase in sucroseenhanced hydrogen peroxide tolerance of Rhodococcus sp. strain APG1, a plant-colonizing bacterium. Nitric Oxide 9:1-9

Crawford NM (2006) Mechanisms for nitric oxide synthesis in plants. J Exp Bot 57: $471-478$

Delledonne M, Xia Y, Dixon RA, Lamb C (1998) Nitric oxide functions as a signal in plant disease resistance. Nature 394:585-588

Deng XG, Zhu T, Zou LJ, Han XY, Zhou X, Xi DH, Zhang DW, Lin HH (2016) Orchestration of hydrogen peroxide and nitric oxide in brassinosteroidmediated systemic virus resistance in Nicotiana benthamiana. Plant J 85:478493

Fan X, Jia L, Li Y, Smith SJ, Miller AJ, Shen Q (2007) Comparing nitrate storage and remobilization in two rice cultivars that differ in their nitrogen use efficiency. J Exper Botany 58:1729-1740

Fang P, Lu RF, Sun F, Lan Y, Shen WB, Du LL, Zhou YJ, Zhou T (2015) Assessment of reference gene stability in rice stripe virus and rice black streaked dwarf virus infection rice by quantitative real-time PCR. Virol J 12:175-185

Feechan A, Kwon E, Yun BW, Wang Y, Pallas JA, Loake GJ (2005) A central role for S-nitrosothiols in plant disease resistance. Proc Natl Acad Sci U S A 102:80548059

Feng Z, Kang H, Li M, Zou L, Wang X, Zhao J, Wei L, Zhou N, Li Q, Lan Y, Zhang Y, Chen Z, Liu W, Pan X, Wang GL, Zuo S (2019) Identification of new rice cultivars and resistance loci against rice black-streaked dwarf virus disease through genome-wide association study. Rice 12(1):49

Forrester MT, Thompson JW, Foster MW, Nogueira L, Moseley MA, Stamler JS (2009) Proteomic analysis of S-nitrosylation and denitrosylation by resinassisted capture. Nat Biotechnol 27:557

Freschi L (2013) Nitric oxide and phytohormone interactions: current status and perspectives. Front Plant Sci 4:398

Gaupels F, Angarakoola GT, Durner J (2011) Upstream and downstream signals of nitric oxide in pathogen defence. Curr Opin Plant Biol 14:707-714

Gupta KJ, Fernie AR, Kaiser WM, Dongen JT (2011) On the origins of nitric oxide. Trends Plant Sci 16:160-168

Han B, Yang Z, Xie YJ, Nie L, Cui J, Shen WB (2014) Arabidopsis HY1 confers cadmium tolerance by decreasing nitric oxide production and improving iron homeostasis. Mol Plant 7:388-403
He Y, Zhang H, Sun Z, Li J, Hong G, Zhu Q, Zhou X, MacFarlane S, Yan F, Chen J (2017) Jasmonic acid-mediated defense suppresses brassinosteroid-mediated susceptibility to Rice black streaked dwarf virus infection in rice. New Phytol 214:388-399

Hibino H (1996) Biology and epidemiology of rice viruses. Annu Rev Phytopathol 34:249-274

Hong JK, Yun BW, Kang JG, Raja MU, Kwon E, Sorhagen K, Chu C, Wang Y, Loake GJ (2008) Nitric oxide function and signaling in plant disease resistance. J Exp Bot 59:147-154

Jaffrey SR, Snyder SH (2001) The biotin switch method for the detection of Snitrosylated proteins. Science's STKE pl1

Ji Y, Liu J, Xing D (2016) Low concentrations of salicylic acid delay methyl jasmonate-induced leaf senescence by up-regulating nitric oxide synthase activity. J Exp Bot 67:5233-5245

Johnson EG, Sparks JP, Dzikovski B, Crane BR, Gibson DM, Loria R (2008) Plantpathogenic Streptomyces species produce nitric oxide synthase-derived nitric oxide in response to host signals. Chem Biol 15:43-50

Klessig DF, Durner J, Noad R, Navarre DA, Wendehenne D, Kumar D, Trifa Y (2000) Nitric oxide and salicylic acid signaling in plant defense. Proc Natl Acad Sci 97:8849-8855

Kong W, Huang C, Chen Q, Zou Y, Zhang J (2012) Nitric oxide alleviates heat stress-induced oxidative damage in Pleurotus eryngii var. tuoliensis. Fungal Genet Biol 49(1):15-20.

Lan Y, Li YW, E ZG, Sun F, Du LL, Xu QF, Zhou T, Zhou YJ, Fan YJ (2018) Identification of virus-derived siRNAs and their targets in RBSDV-infected rice by deep sequencing. J Basic Microbiol 58: 227-237

Lee BC, Hong YK, Hong SJ, Park ST, Lee KW (2005) Occurrence and detection of rice black-streaked dwarf virus in Korea. Plant Pathol J 21:172-173

Li Z, Liang WS, Carr JP (2014) Effects of modifying alternative respiration on nitric oxide-induced virus resistance and PR1 protein accumulation. J Gen Virol 95: 2075-2081

Lindermayr C, Saalbach G, Durner J (2005) Proteomic identification of Snitrosylated proteins in Arabidopsis. Plant Physiol 137:921-930

Lindermayr C, Sell S, Müller B, Leister D, Durner J (2010) Redox regulation of the NPR1TGA1 system of Arabidopsis thaliana by nitric oxide. Plant Cell 22:2894-2907

Liu N, Gong B, Jin Z, Wang X, Wei M, Yang F, Li Y, Shi Q (2015) Sodic alkaline stress mitigation by exogenous melatonin in tomato needs nitric oxide as a downstream signal. J Plant Physiol 186:68-77

Livak KJ, Schmittgen TD (2001) Analysis of relative gene expression data using real-time quantitative $P C R$ and the 2- $\Delta \Delta C T$ method. Methods 25:402-408

Lozano-Juste J, León J (2009) Enhanced abscisic acid-mediated responses in nialnia2noa1-2 triple mutant impaired in NIA/NR- and AtNOA1-dependent nitric oxide biosynthesis in Arabidopsis. Plant Physiol 52:891-903

Lozano-Juste J, León J (2010) Nitric oxide modulates sensitivity to ABA. Plant Signal Behavior 5:314-316

Lu RF, Liu ZY, Fang P, Chen GY, Sun F, Fan YJ, Zhou YJ, Zhou T (2016) Reference genes: essential criteria for assessment of the real-time PCR based virus detection in plants virology. Br J Virol 3:6-10

Mur LA, Carver TL, Prats E (2006) NO way to live; the various roles of nitric oxide in plant-pathogen interactions. J Exp Bot 57:489-505

Mur LA, Santosa IE, Laarhoven LJ, Holton NJ, Harren FJ, Smith AR (2005) Laser photoacoustic detection allows in planta detection of nitric oxide in tobacco following challenge with avirulent and virulent pseudomonas syringae pathovars. Plant Physiol 138:1247-1258

Nakayama A, Fukushima S, Goto S, Matsushita A, Shimono M, Sugano S, Jiang CJ, Akagi A, Yamazaki M, Inoue H, Takatsuji H (2013) Genome-wide identification of WRKY45-regulated genes that mediate benzothiadiazole-induced defense responses in rice. BMC Plant Biol 13:150

Neill SJ, Desikan R, Clarke A, Hancock JT (2002) Nitric oxide is a novel component of abscisic acid signaling in stomatal guard cells. Plant Physiol 128:13-16

Novák O, Floková K (2018) An UHPLC-MS/MS Method for Target Profiling of Stress-Related Phytohormones. In: Carla A (ed) Plant Metabolomics: Methods and Protocols, Methods in Molecular Biology, vol 1778. Springer science+ business media, Heidelberg

Pan G, Liu YQ, Ji LS, Zhang X, He J, Huang J, Qiu Z, Liu D, Sun Z, Xu T, Liu L, Wang C, Jiang L, Cheng X, Wan J (2018) Brassinosteroids mediate susceptibility to brown planthopper by integrating with salicylic acid and jasmonic acid pathways in rice. J Exp Bot 69:4433-4442

Parani M, Rudrabhatla S, Myers R, Weirich H, Smith B, Leaman DW, Goldman SL (2004) Microarray analysis of nitric oxide responsive transcripts in Arabidopsis. Plant Biotechnol J 2(4):359-366. 
Perchepied L, Balagué C, Riou C, Claudel-Renard C, Rivière N, Grezes-Besset B, Roby D (2010) Nitric oxide participates in the complex interplay of defense-related signaling pathways controlling disease resistance to Sclerotinia sclerotiorum in Arabidopsis thaliana. Mol Plant-Microbe Interaction 23:846-860

Qi F, Xiang ZX, Kou NH, Cui WT, Xu DK, Wang R, Zhu D, Shen WB (2017) Nitric oxide is involved in methane-induced adventitious root formation in cucumber. Physiol Plant 159:366-377

Qi JF, Li JC, Han X, Li R, Wu JQ, Yu HX, Hu LF, Xiao YT, Lu J, Lou YG (2016) Jasmonic acid carboxyl methyltransferase regulates development and herbivory-induced defense response in rice. J Integr Plant Biol 58:564-576

Sanz L, Fernándezmarcos M, Modrego A, Lewis DR, Muday GK, Pollmann S, Dueñas M, Santos-Buelga C, Lorenzo O (2014) Nitric oxide plays a role in stem cell niche homeostasis through its interaction with auxin. Plant Physiol 166:1972-1984

Šašek V, Janda M, Delage E, Puyaubert J, Guivarc'h A, López ME, Dobrev PI, Caius J, Bóka K, Valentová O, Burketová L, Zachowski A, Ruelland E (2014) Constitutive salicylic acid accumulation in pi4kIII $1 \beta 2$ Arabidopsis plants stunts rosette but not root growth. New Phytol 203:805-816

Schmidt HH, Walter U (1994) NO at work. Cell 78:919-925

Shikata E, Kitagawa Y (1977) Rice black-streaked dwarf virus: its properties, morphology and intracellular localization. Virology 77:826-842

Shimono M, Koga H, Akagi AYA, Hayashi N, Goto S, Sawada M, Kurihara T, Matsushita A, Sugano S, Jiang CJ, Kaku H, Inoue H, Takatsuji H (2012) Rice WRKY45 plays important roles in fungal and bacterial disease resistance. Mol Plant Pathol 13:83-94

Shimono M, Sugano S, Nakayama A, Jiang CJ, Ono K, Toki S, Takatsuji H (2007) Rice WRKY45 plays a crucial role in benzothiadiazole-inducible blast resistance. Plant Cell 19:2064-2076

Simontacchi M, Galatro A, Ramosartuso F, Santa-María GE (2015) Plant survival in a changing environment: the role of nitric oxide in plant responses to abiotic stress. Front Plant Sci 6:260-268

Song F, Goodman RM (2001) Activity of nitric oxide is dependent on, but is partially required for function of, salicylic acid in the signaling pathway in tobacco systemic acquired resistance. Mol Plant-Microbe Interact 14:14581462

Sugano S, Jiang CJ, Miyazawa S, Masumoto C, Yazawa K, Hayashi N, Shimono M, Nakayama A, Miyao M, Takatsuji H (2010) Role of OsNPR1 in rice defense program as revealed by genome-wide expression analysis. Plant Mol Biol 74: 549-562

Sun H, Bi Y, Tao J, Huang S, Hou M, Xue R, Liang Z, Gu P, Yoneyama K, Xie X, Shen Q, Xu G, Zhang Y (2016) Strigolactones are required for nitric oxide to induce root elongation in response to nitrogen and phosphate deficiencies in rice. Plant Cell Environ 39:1473-1484

Takatsuji H (2014) Development of disease-resistant rice using regulatory components of induced disease resistance. Front Plant Sci 5:630

Tossi V, Lamattina L, Cassia R (2009) An increase in the concentration of abscisic acid is critical for nitric oxide-mediated plant adaptive responses to UV-B irradiation. New Phytol 181:871-879

Wilkinson JQ, Crawford NM (1991) Identification of the Arabidopsis CHL3 gene as the nitrate reductase structural gene NIA2. Plant Cell 3:461-471

Wilkinson JQ, Crawford NM (1993) Identification and characterization of a chlorate-resistant mutant of Arabidopsis thaliana with mutations in both nitrate reductase structural genes NIA1 and NIA2. Mol Genet Genomics 39: 289-297

Xie YJ, Mao Y, Lai DW, Zhang W, Zheng TQ, Shen WB (2013) Roles of NIA/NR/ NOA1-dependent nitric oxide production and HY1 expression in the modulation of Arabidopsis salt tolerance. J Exp Bot 64:3045-3060

Xie YJ, Mao Y, Zhang W, Lai DW, Wang QY, Shen WB (2014) Reactive oxygen species-dependent nitric oxide production contributes to hydrogenpromoted stomatal closure in Arabidopsis. Plant Physiol 165:759-773

Xie K, Li L, Zhang H, Wang R, Tan X, He Y, Hong G, Li J, Ming F, Yao X, Yan F, Sun $Z$, Chen J (2018) Abscisic acid negatively modulates plant defence against rice black-streaked dwarf virus infection by suppressing the jasmonate pathway and regulating reactive oxygen species levels in rice. Plant Cell Environ 41(10):2504-2514.

Yun BW, Feechan A, Yin MH, Saidi NBB, Le BT, Yu MD, Moore JW, Kang JG, Kwon E, Spoel SH, Pallas JA, Loake GJ (2011) S-nitrosylation of NAPDH oxidase regulates cell death in plant immunity. Nature 478:264-268

Zhang Z, Wang JY, Chai RY, Qiu HP, Jiang H, Mao XQ, Wang YL, Liu FQ, Sun GC (2015) An S-(hydroxymethyl) glutathione dehydrogenase is involved in conidiation and full virulence in the rice blast fungus Magnaporthe oryzae. PLoS One 10:e0120627

Zhao CC, Cai SG, Wang YZ, Chen ZH (2016) Loss of nitrate reductases NIA1 and NIA2 impairs stomatal closure by altering genes of core ABA signaling components in Arabidopsis. Plant Signal Behav 11:e1183088

Zhao G, Zhao YY, Yu XL, Kiprotich F, Han H, Guan RZ, Wang R, Shen WB (2018) Nitric oxide is required for melatonin-enhanced tolerance against salinity stress in rapeseed (Brassica napus L.) seedlings. Int J Mol Sci 19:1912

Zhao MG, Chen L, Zhang LL, Zhang WH (2009) Nitric reductase-dependent nitric oxide production is involved in cold acclimation and freezing tolerance in Arabidopsis. Plant Physiol 151:755-767

Zhou Y, Liu H, Wang G, Huang X, Cheng Z, Chen Z, Zhou X (2004) Immunological detection of rice trip virus carried by Laodephax striatellus Fallen. Jiangsu Agric Sci 1:52-53.

Zhou T, Wang Y, Wu LJ, Fan YJ, Zhou YJ (2011) The research on method of artificial inoculation and identification on rice resistance to rice black dwarfstreaked virus. Acta Phytophylacica Sinica 4:301-305

Zhou T, Wu L, Wang Y, Cheng ZB, Ji YH, Fan YJ, Zhou YJ (2010) Preliminary report on the transmission of rice black-streaked dwarf virus from frozen infected leaves to rice by insect vector small brown planthopper (Laodelphax striatellus). Chinese J Rice Sci 24:425-428

Zou LJ, Deng XG, Zhang LE, Zhu T, Tan WR, Muhammad A, Zhu L, Zhang C, Zhang DW, Lin HH (2018) Nitric oxide as a signaling molecule in brassinosteroid-mediated virus resistance to cucumber mosaic virus in Arabidopsis thaliana. Physiol Plant 163:196-210

\section{Publisher's Note}

Springer Nature remains neutral with regard to jurisdictional claims in published maps and institutional affiliations.

\section{Submit your manuscript to a SpringerOpen ${ }^{\circ}$ journal and benefit from:}

- Convenient online submission

- Rigorous peer review

- Open access: articles freely available online

High visibility within the field

- Retaining the copyright to your article

Submit your next manuscript at $\boldsymbol{\nabla}$ springeropen.com 